\title{
The Teaching Reform of Medicinal Botany
}

\author{
Sun Kunlai ${ }^{\mathrm{a}}$, Chen Yin, Qu Youle, Yang Zuisu, Yang Liye \\ School of Food and Medicine \\ Zhejiang Ocean University \\ Zhoushan 316022 China \\ a sunqinlai@126.com
}

\begin{abstract}
Explore the new teaching model of "medicinal botany", so as to enhance the students' interest in this course and their comprehensive practice, innovation and application ability. Establish the student-oriented teaching philosophy, introduce comprehensive experiment and exploratory experiment, innovate the outdoors practice content and establish the diversified comprehensive examination mode. Greatly enhance the students' enthusiasm and subjective initiative; develop students' ability to find problems, analyze problems and solve problems; improve the students' outdoor observation ability, hands-on practical and teamwork ability; consciously strengthen the practical ability and scientific research ability, so as to make the course more targeted, practical and technical, laying a solid foundation for the students to develop comprehensive professional ability.
\end{abstract}

Keywords-Pharmaceutical Botany; Teaching Reform; Comprehensive Practice; Improve Efficiency

\section{INTRODUCTION}

Medicinal botany is a science to study the form, tissue, physiological function, classification identification, cell tissue culture, resource development and rational utilization of plants with medical care function. The task is to systematically learn the knowledge of botany, study the classification and identification of medicinal plants, investigate the medicinal plant resources, sort the types of Chinese herbs, ensuring the accurate and effective use of medicinal plants[1]. This course is the basic course of specialties such as medicine, Chinese materia medica, pharmaceutical engineering, and has indivisible close relationship with professional courses such as identification science of TCM, TCM, traditional Chinese medicine resources, pharmacognosy, natural pharmaceutical chemistry[2]. However, the content of the course is boring and has many entries, many knowledge require rote. This has decreased students' interest in it, and resulted in less interaction between teachers and students, depressing classroom atmosphere, and poor learning effect. This teaches adopt the "cramming" method of teaching, and students only know theory, but do not understand the actual reality. This also violates the subject's purpose of applicability and practicality[3]. In order to make the abstract boring difficulties easy to understand and memorize, motivate the students' learning interest and activeness, improve the quality of teaching, the author conducts thinking and preliminary reform discussion from basic teaching idea, experimental operation, outdoor practice and comprehensive evaluation.

This work was financially supported by Zhejiang Provincial Natural Science Foundation No. LQ18D060005

\section{UPDATE THE TEACHING CONCEPT TO HIGHLIGHT THE STUDENT-ORIENTED TEACHING IDEA}

\section{A. Disadvantages of traditional teaching concepts}

Pharmaceutical botany is the basic course of specialties such as pharmacy and Chinese materia medica. The traditional way of teaching basically focuses on theory teaching, helps students understand the basic knowledge through teachers' explanation in class, and then links theory with practice. But this kind of traditional teaching model can't well adapt to the discipline of medical botany with strong practicalness. It is difficult to let students have impressive understanding of the abstract boring evolution of primary and secondary structures, complicated leaf morphology and flower types, common but unfamiliar plant classification, familiar but inaccurate-mastered common traditional Chinese medicine functions with theoryoriented teaching method. It is more difficult to use the method to stimulate students' interest in learning and exploring on pharmaceutical botany.

\section{B. Explore new class mode}

Medicinal botany has numerous knowledge points which are closely related, it is easy for teachers' long theory to cause dull classroom climate and reduce students' interest in learning. Therefore, in the process of theoretical teaching, teachers should make full use of various teaching methods to let students have more vivid and profound understanding of abstract words in textbooks, such as showing leaf and flower types with image, playing the growth process of primary and secondary structures with video. In addition, in the explanation of some medicinal plants, teacher can appropriately tell some folk legends and anecdotes about the plants to combine the boring theoretical knowledge with rich vivid reality, improving the students' learning interest and deepening their impression of the plants' medicinal effect.

Change the traditional "cramming" teaching to more selfdirected "discussing" class. According to the requirements of the curriculum, introduce the basic characteristics and learning points of highlighted plant species first, and then divide students into four study groups. Members of each study group need to divide the work to check the information discuss and make multimedia courseware. Each group students need to show the learning materials they collect to other students in multimedia way and other students can actively ask questions and discuss in the process of displaying. After that, teachers summarize and evaluate the displaying, and outline the key 
points again, put forward the corresponding improvements for the existing problems. This kind of teaching mode has changed the traditional inflexible teaching method, greatly enhanced the students' learning enthusiasm and subjective initiative, and improved the students' logical ability and cooperation ability to find problem, analyze problem and solve problems, making their mastered knowledge more impressive.

In addition, teachers can also approximately introduce subject frontier knowledge in the teaching process, explain the process of new drugs from basic research to development and application to train their macroscopic system of knowledge and lay a good foundation for them to become professional talents with solid knowledge. For example, the discovery and application of taxol in the taxus chinensis, allows students to have a clear understanding of the research process of natural medicine and its practical application. Through the interpretation of the current high-end technology, improve students' interest in learning, inspire students to form systematic logical and thinking way to explore the unknown system, enlighten them to form the innovation methods to solve practical problems.

\section{Combine theoretical teaching with practical teaching}

In order to improve the teaching quality of this course, we must adhere to the combination of theory and practice, focus on the practical education, and gradually improve the comprehensive quality of students. During the implementation of practical education, we should be closely around the purpose of improving students' practical ability, develop feasible teaching plan and syllabus, optimize the practice project, increase the comprehensive experiment, and select field practice spot, so as to ensure the improvement of students' practical ability[4]. For example, in the process of teaching, I organize students to carry out the activity of "campus medicinal flora", and divide students into groups of four. Each group is assigned an area of campus with rich plant species to conduct investigation and get conclusion. In the end, collect the investigation results of eight groups of the class to form a simple "campus medicinal flora". Though the "flora" is simple and crude, each student has to do careful observation and comparison, consult literature, take photos of plant feature, make specimens, have discussions in the process. The whole investigation stimulates their curiosity, trains their observation ability, at the same time allows them to apply the knowledge of plant organ types, plant classification that they learn in theory courses to practice; during the preparation of the specimen, the knowledge of proving experiment is applied again, and the efficacy and application of each medicinal plant is obtained through literature investigation. After the formation of "campus medicinal flora", every student can experience the joy of success and the joy of making efforts. This is a relatively comprehensive and integrated teaching attempt. After a semester, I can clearly feel that students' love for this course has increased; the practical ability and independent thinking ability of students have been improved. At the same time, students' interest in this course will also has positive influence on the studying of other professional courses, such as pharmacognosy and natural pharmaceutical chemistry.

\section{EXPERIMENTAL REFORM IS IMPERATIVE, AND INTRODUCES COMPREHENSIVE EXPERIMENT AND EXPLORATORY EXPERIMENT}

\section{A. Verification experiments cannot be carried out only in one way}

Traditional pharmaceutical botany experiments are mostly verification experiments. The purpose of verification experiment is designed to allow students to verify the result of the experiment in order to consolidate the textbook knowledge. It is usually carried out under a designed complete experiment framework. Process and matters needing attention are developed in advance and are very strict. The students' subjective initiative is relatively small[5]. At the same time, the verification experiment has obvious phenomena and results. Most students just walk through the process and muddle through their work, lack of detailed analysis of experiment principles and strict logical reasoning of experimental result, which makes the experiment course become a mere formality, difficult to achieve the desired effect.

And basic model of traditional experiment teaching is that teacher explains and demonstrates and students just follow the teacher and operate according to the fixed process step by step. Some students even don't understand the experiment, making it become a mere formality. This kind of teaching method can't bring about students' interest in learning, and even causes students to be idle in thinking about the content and methods of the experiment.

\section{B. Appropriately introduce comprehensive experiment and exploratory experiment}

In the process of teaching, though the basic experimental technology and verification experiments are essential, they can't occupy all of the experimental courses. It is imperative to appropriately introduce comprehensive experiment and highly autonomous exploratory experimental project.

Comprehensive experiments take basic experimental technology as its premise, and are the extension for the verification experiment. It allows students to have deeper understanding of the distribution characteristics of all kinds of medicinal plants and the diversity of species through comprehensive comparative analysis of all kinds of plants and in-class study and after-class practice operation[6]. Exploratory experiment is characterized by openness. It often requires students to work together to complete. It can cultivate students' ability to identify problems, analyze problems and solve problems. Set a research direction, and ask students to design experimental steps, perfect experimental process, access to information and analyze results in an innovative way under the premise of independent assumption. It shows the gaining process of scientific results in normal scientific research. Students can have stronger sense of participation in experiment, and obtain the real objective scientific experiment experience, so as to enhance the exploration enthusiasm and scientific research ability of students in a solid and effective way. 


\section{CARRY OUT INNOVATIVE FIELD PRACTICE TO CULTIVATE COMPREHENSIVE ABILITY}

The close relationship between medicinal botany and real life determines that its learning style must be combined with the field growth environment, careful observation and classification of the plants. After learning the basic theoretical knowledge of textbooks, it is essential to observe, classify and remember the organs of plants such as roots, stems and leaves in the wild. In the practical process, discuss and analyze the medicinal value and research direction of the plants. The active learning atmosphere can improve the students' interest in learning; consolidate the understanding of the key basic knowledge.

There are many choices of field practice spot, such as nearby campus, which is really convenient. There are abundant plant resources in campus, and teachers can take students to practice in campus after finishing the theory course. In order to improve the students' interests, during the practice in the school, teachers can guide students to make specimens of leaves, prepare simple plant retrieval list. It is the most convenient field practice method to train students to identify medicinal plants to take full advantage of plant resources in campus.

In addition, we can choose mountain forest and grassland with rich medicinal plants as the field of practice. Before practice, teachers first explain the basic characteristic of the main species and matters needing attention, and students look up the weather and vegetation type of the field according to practice objectives and tasks and prepare various tools that may need. For example, divide students into four groups in field practice, and each group designs different collection routes. Then students observe and collect fresh field plants according to teachers' explanation and their preparation before class, discuss and record the main characteristics, so as to deepen the understanding of the plants. Plants that need to be observed with experimental equipment can be collected for further research in laboratory and made into specimen. Each group gets together after finishing the observation and collection to let the teacher to explain the plant species which students are not sure of. Collect samples in groups and solve the problems together. This way not only can develop students' interest and learning initiative, but also allows students to know more plant species. After class, students can add incomplete information, and deepen the impression of these plants through the preparation and exhibition of specimens and labeling of the medicinal value.

The field practice can help students directly observe plants' true state of survival, increase learning experience that cannot be felt in classroom learning. Therefore, students' learning enthusiasm has run high. It not only deepens students' understanding of theoretical knowledge and application, but also trains students' ability of field observations, hands-on practice and team cooperation.

\section{ESTABLISH DIVERSIFIED COMPREHENSIVE ASSESSMENT FORM}

As an important part of teaching process, test and examination is directly related to the assessment of teaching quality and the examination of students' learning effect.
Pharmaceutical botany has strong practicalness, and should design reasonable examination form through close combination of the teaching purpose of this subject and its teaching characteristics.

Previous experiments result, and usual grades and experiment examination scores each accounts for 50\%. Usual grades mainly come from experiment report. Such way of assessment is too flat and single, and doesn't have comprehensive evaluation index. Therefore, students prefer the writing of experiment report and its results, and reduce thinking about the experimental operation and process. This has put the cart before the horse, and makes the examination become a mere formality, hard for it to cover the students' comprehensive ability.

Therefore, it is necessary to establish a reasonable and diversified assessment system, which can be divided into three aspects: first is usual attendance, class discussion and outdoor internship, accounting for 30\%; second is the writing of experimental report, accounting for $10 \%$, which is more biased towards the accuracy and scientificity of the experimental results; third is the final exam score, accounting for $70 \%$, which mainly examines the students' practical ability and the comprehensive performance of written exam. The practical ability includes observing plant section and pointing out the corresponding name, drawing diagram and marking. The design of closed-book written examination has strengthened the assessment of course and comprehensive application ability of knowledge, reflecting student's ability to grasp the basic knowledge and skills.

This comprehensive evaluation system can comprehensively and objectively assess students' mastery of theoretical knowledge and operative skills, so as to give full play to students' main body role, urge students to study hard, conscientiously strengthen their hands-on practical ability and scientific research abilities.

\section{CONCLUSION}

Above are some teaching experiences that the author has accumulated in teaching practice and some teaching explorations made in the process. Each teaching reform should adjust measures to local conditions, vary from person to person. It should pay attention to communication with students in the practice process, timely collect feedback, find defects and improve the defects of the course, so as to raise teachers' own teaching level unceasingly and enhance students' learning enthusiasm and scientific research ability, laying a solid foundation for students to become professional talents with solid knowledge.

\section{REFERENCES}

[1] Zhang Hao, Chen Jianchun, Huang Baokang. Medicinal botany (6th edition) [M]. Beijing: People's Medical Publishing House, 2011.7.(In Chinese)

[2] Yang Chunshu, Zeng Wanzhang, Liu Wenliang, etc. Medicinal botany [M]. Shanghai: Shanghai Science and Technology Press, 1997:1-4. (In Chinese) 
[3] Xiong Wanxi. A case study of the education reform in the United States in the 1960s and 1970s-from the perspective of University of California Santa Cruz (UCSC) [J]. Foreign Education Research, 2009, (11) : 72. (In Chinese)

[4] Huang Dafang. A preliminary study on teaching reform of medicinal botany $[\mathrm{J}]$. Guiding Journal of Traditional Chinese Medicine and Pharmacology, 2006, 12(3) : 91-93. (In Chinese)
[5] Lei Wu, Yang Liu, Hai-jun Jia, Jun Wang. Innovative flow-resistance performance in the single-phase natural circulation loop and relevant experiment verification[J]. International Journal of Heat and Mass Transfer, 2017, 107: 66-73.

[6] Liu Wenyuan, Li Zhiyu. The design of comprehensive experiments on pharmaceutical science under the background of deepening innovation and entrepreneurship education[J]. Pharmacology Education, 2016, 2(32) : 61-63. (In Chinese) 